\title{
Research of recirculation systems and air recovery systems
}

\author{
G.S. Abiyeva ${ }^{1}$, G.B. Aldabergenova ${ }^{2}$, and B.A. Balapanov ${ }^{3}$ \\ ${ }^{1}$ Kyzylorda University named after Korkyt Ata, Kyzylorda, Kazakhstan \\ ${ }^{2}$ International Educational Corporation (KazGASA), Almaty, Kazakhstan \\ ${ }^{3}$ Kyzylorda University named after Korkyt Ata, Kyzylorda, Kazakhstan
}

\begin{abstract}
The scientific work "Research of recirculation systems and air recovery systems" is devoted to the analysis and selection of the most optimum ventilation systems that will reduce the cost of published products by reducing energy consumption. The purpose of this work is to discover and experimentally study the characteristics that affect the use of thermal and electric energy by ventilation systems and air heating in the industry, as well as to create solutions that allow to achieve a decrease in the consumption of fuel and energy resources for these systems. The relevance of the work is to reduce the cost of manufactured products and increase their own competitiveness by saving consumed energy resources. In this regard, the development of completely new solutions focused on the economic efficiency of electrical and thermal energy in ventilation and heating systems in various industries, with a simultaneous increase in sanitary hygienic efficiency, today is an urgent task of solving the problem and has economic national importance.
\end{abstract}

\section{Introduction}

At this time, energy efficiency is one of the main characteristics of any project.

In the design development, energy-saving tasks were assigned a separate chapter with specific descriptions and calculations, and today, separate sections of technical and commercial proposals are devoted to energy-saving technologies and equipment.

The issue of energy conservation is considered an important issue in the air conditioning systems of the data center and the refrigeration capacity of the equipment reaches $10 \mathrm{MW}$ during this period. This paper discusses new technological processes to optimize their work.

The revival of the domestic industry, on a par with the main modernized technological processes and equipment, is impossible without an important reduction in thermal energy consumption, while simultaneously providing satisfactory labor ratings.

According to such fundamental indicators as the total energy consumption, which is consumed per unit of output, the Republic of Kazakhstan at the moment lags far behind the leading industrially civilized countries of the world. In industrial enterprises, ventilation heating systems are a significant and main consumer of electrical and thermal energy. As a consequence, a decrease in energy consumption by ventilation and heating systems will reduce the cost of production and increase its competitiveness. 
It is impossible to ignore the problem of the sanitary and hygienic nuance. Negative labor circumstances, including an increase in the concentration of dust, as well as high air pollution at workplaces, lead to a decrease in labor productivity. And it is impossible without productive ventilation of the enterprise receiving the worldwide international quality certificate ISO 9000 .

It should also be noted that the use of effective ventilation systems makes it possible not only to catch harmful substances, but also to localize harmful substances released during technological production, which of course minimizes the amount of harmful substances entering the air and enhances the environmental situation.

Purpose of work: detection and experimental study of characteristics that affect the use of heat and electric energy by ventilation systems and air heating in the industry, as well as the creation of solutions that allow to achieve a reduction in the consumption of these systems of fuel and energy resources.

The objectives of the research are: analyze the possibilities of lowering the fuel and energy systems, taking into account the annual cycle of work; to study the system of formation of temperature fields and concentrations of impurities in buildings; to identify technological ways of controlling the air-thermal system of various buildings; to create and extensively introduce items that will significantly reduce the fuel and energy consumption of ventilation and heating systems in the industry; to design proposals for the distribution of operating modes of ventilation and heating systems, their calculation and project planning.

\section{Research of recirculation systems and air recovery systems}

Saving energy resources is one of the most pressing issues today, pushing for the creation and use of economical equipment or re-sale of already used energy in many areas of service and production. Energy efficient ventilation systems are no exception in this case. When developing a ventilation system project, it is imperative to remember that operating costs may be reduced by recycling thermal energy resources.

It is possible to extract secondary energy in ventilation systems by using heat or cold from technological units, if they are suitable for use, as well as by using heat or cold from the air, which in turn is removed by the ventilation system. In ventilation systems, to save energy, heat exchangers (heat exchangers) may be used, which are of three or more types: cross-flow recuperators (plate), rotary (regenerative), recuperators.

In plate heat exchangers, the removed and supplied clean air passes from the edge of the plates and here the air flows do not interact with each other. Gas condensate may form on the plates, for this reason they are enhanced with special taps. Such condensate collectors, equipped with a water seal, do not allow the fan, together with air currents, to capture water and redirect it into the channel. Moreover, possible condensation build-up includes the presence of a freezing system in the event of ice formation. Heat recovery is controlled by a bypass valve, which controls the flow rate of the passing air. The plate heat exchanger is characterized by an efficiency of work equal to - 50-90\%.

In rotary recuperators, heat rotates between the supply and exhaust channels and moves due to the rotor. Due to the rotor speed, the level of heat recovery is monitored. The efficiency of a recuperative heat exchanger should not exceed $75-85 \%$.

For example: Recuperator MarleyMEnV 180 is a device for ventilation and enhancement of the internal microclimate of the house. Marley recovers heat from the outside air and enriches the outside air with heat. During this, about $85 \%$ of the heat returns to the room. The house is constantly ventilated: a complete air change is made within two hours.

The main advantage of the MarleyMEnV 180 recuperator lies in the air quality control: the ceramic element of the recuperator utilizes excess moisture together with non-processed 
masses, the air from dust, odors, harmful emissions at the inlet is cleaned by filters, as in Figure 1.

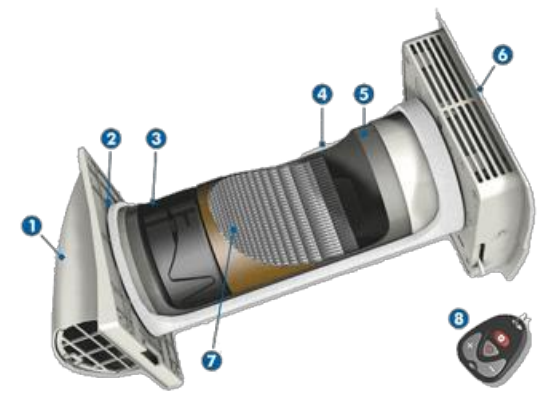

Fig. 1. MarleyMEnV 180 Recuperator

Ventilation of MarleyMEnV 180 consists of:

1. External casing. The casing protects the wall section from precipitation, sunlight, insects and dust;

2. A fan that ensures the constant operation of the heat exchanger for ventilation in three modes;

3. G3 or G4 grade filter;

4. Insulated casing, which prevents condensate deposition and freezing of the heat exchanger, for ventilation at subzero temperatures (functions at temperatures up to -30 degrees);

5. Enclosure, which is installed pursuant to the thickness of the outer wall;

6. Decorative panel with switch;

7. Ceramic cell element with an enlarged configuration. Due to the increased contact area, cold air is rather heated to the required temperature before entering the room;

8. Remote control unit.

The disadvantage of this design is the low efficiency of the process of processing air with thermal humidity in the winter period of the year.

The technical result is greater efficiency and, herewith, reduced energy consumption of the thermal humidity of the processed air in the winter season.

Figure 2 shows a general plan of the existing energy saving ventilation system, Figure 3 - top view

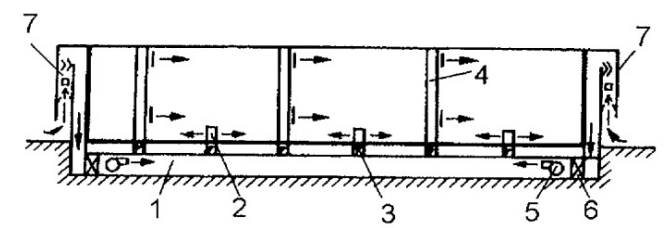

Fig. 2. General view of the energy-saving ventilation system

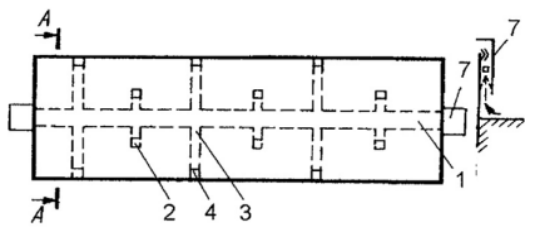

Fig. 3. Top view of an energy-saving ventilation system 
The operating automatic damper constantly changes the direction of the air flow 1 time in $1 \ldots 1.5$ minutes. Such a design is compact and the cost of the material of the nozzles may fully compensate for the additional costs of the damper, which explains the high energy efficiency of the heat exchanger.

Moreover, a ventilation system with a recuperator is mandatory for individual energysaving houses in Figure 4.

The principle of recovery is based on the use of exhaust heat air. With the help of heat exchangers, heat transfer appears, which are distinguished by the type of implementation and the way of air movement.

According to the type of heat recovery equipment, the following equipment is used:

In the process of the tested designs of energy-saving devices, there are regenerative heat exchangers, which have a polyethylene film in the heat-transmitting surfaces, as well as, possibly, regenerative heat exchangers with nozzles, which consist of alternating corrugated sheets made of materials with the highest coefficient of absorption.

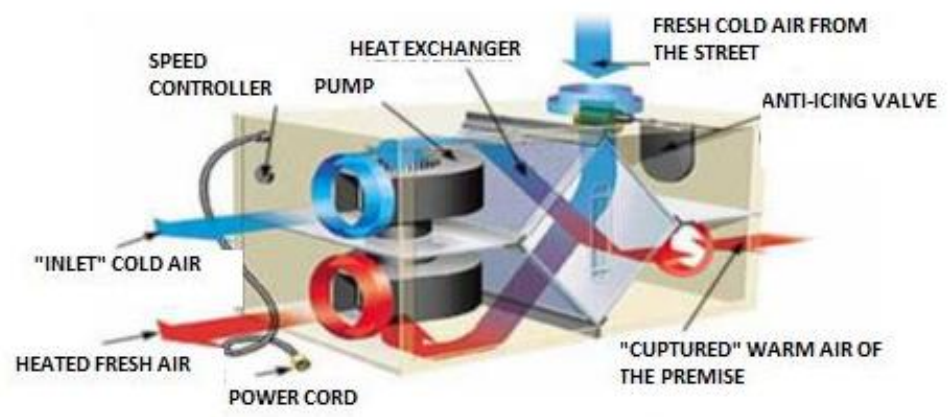

Fig. 4. Ventilation system with the recuperator

This design is made of aluminum alloy plates, which develop a duct system for the flow of air. It is with a high thermal conductivity of the channel walls that the transfer of heat from the supply air from the exhaust air appears. The efficiency of existing equipment may be up to $70 \%$ in Figure 5.
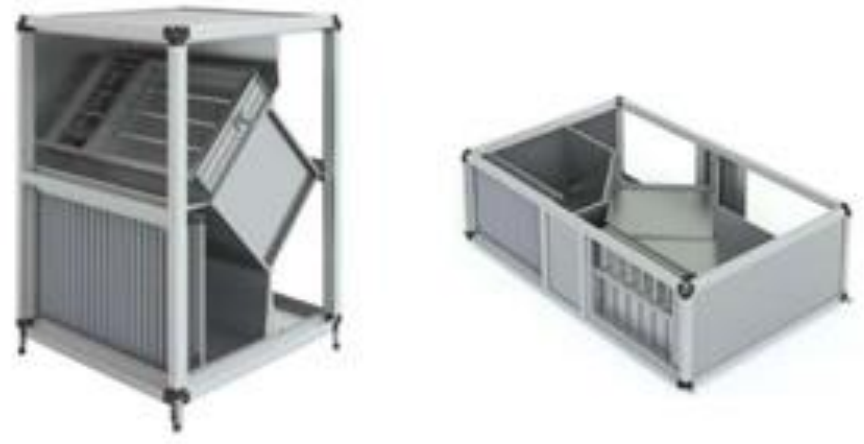

Fig 5. Plate recuperator

The rotary recuperator structure is designed like a drum, which consists of large multiple aluminum cells that rotate around its axis. This cell heats up if it enters the extract air area. Being in the area of the supply air, the cell gives the heat that has accumulated to the supply air. The efficiency of existing equipment may be up to $85 \%$. 


\section{Conclusion}

Relevance of work: According to experts, ventilation heating systems in the chemical industry consume $10 \%$ of all consumed fuel energy resources, and, for instance, in the shipbuilding industry - up to $70 \%$. It is clear that, having successfully solved the problem of energy conservation, the industry will take care of reducing the cost of manufactured products, and hence increasing its own competitiveness.

In this regard, the development of completely new solutions focused on the economic efficiency of electrical and thermal energy in ventilation heating systems in various industries, with a simultaneous increase in sanitary hygienic efficiency, today is an urgent task of solving the problem and has economic national importance.

Novelty of the research: the relationship of characteristics showing the operation of ventilation heating systems was revealed; a mathematical model of the ventilation system has been developed; the methods were studied for different methods of organizing the exchange of air of the appearance of fields of concentrations of impurities in the volume of the enterprise; methods have been identified that make it possible to assess the appropriate use of air recirculation in various industrial buildings; a mathematical model of the technological process of renewing the existing temperature regime in the shop has been developed and investigated, and methods for increasing the thermal and air load of the system are indicated in detail.

Practical significance: a method for finding and selecting schemes and means of air distribution was created, taking into account the reduction of fuel and energy consumption, and recommendations were given for the development and use of air distribution systems; a method has been developed for using recirculation to find air purification means; designs with built-in air curtains of large-sized gates are proposed, which sharply reduce the infiltration of outside air; constructive solutions are proposed that prevent the penetration of falling flows of cold air into the working area of the room; a method has been found for instant restoration of the temperature regime in the heat regime shops; unique ventilation items with an exhaust hood have been developed, tested and serially produced; developed electrostatic and other filters from dust particles and oil aerosol for air purification; devices for cleaning ventilation air from various impurities of gases. The theory of reducing the use of fuel energy resources by methods of air heating and industrial ventilation, taking into account the entire annual cycle of work; a mathematical model of ventilation processes and the creation on its basis of methods for calculating and controlling the distribution of impurity concentrations and temperatures of an enterprise; general complex of engineering solutions, which allows to reduce the consumption of the energy system of heating and ventilation of various premises.

In the rational use of the fuel energy system in industrial buildings, the main basis is the development of a calculation method and a design solution.

\section{References}

1. G. Ya. Krupkin, E. V. Ivanova, X. J. I. Rodriguez, The air mode of buildings with precision and sterile technologies. Medicine of labor and industrial ecology, U.M., 43 (1995)

2. A. Ya. Kreslin, G. B. Kogan, Automation of conditioners by a method of the optimum modes, Riga: LatMITI, 48 (1990)

3. A. Ya. Kreslin, Optimization of energy consumption of air conditioning systems, Riga: RPI, 154 (1982)

4. E. E. Karpis, Energy saving in air conditioning systems, M.: Stroyizdat, 268 (1986) 
5. E. E. Karpis, Water supply and sanitary equipment, 10, 241 (1989)

6. A. I. Zavyalov, M. O. Steinberg, L. A. Pozdnyakova et al, Modern ways of cleaning of harmful atmospheric emissions, L., LDNTP, 56-58 (1991)

7. A. A. Evstratov, M. I. Grimitlin, G. A. Smirnova et al, Modern ways of cleaning of harmful atmospheric emissions, L., LDNTP (1991)

8. V. N. Denisov, Normalization of the thermal mode of working spaces of installations of prospecting drilling, 42 (1997)

9. R. N. Davydov, V. V. Lukashov, D. S. Provorov et al, III ABOK congress, 149 (1993)

10. A. A. Gusev, A. P. Kylatchanov, I. A. Obukhov, Ecology, energy saving, economy, Perm, 44 (1994)

11. A. A. Gusev, A. P. Kylatchanov, Water supply and sanitary equipment, 6, 13 (1992)

12. M. I. Grimitlin, G. M. Pozin, E. A. Tuomas, Heatgas supply and ventilation, Kaunas, 70 (1991)

13. M. I. Grimitlin, G. M. Pozin, A. M. Grimitlin, Materials of the 4th congress of ABOK, 159 (1995)

14. M. I. Grimitlin, G. M. Pozin, Assessment of efficiency of ventilation systems. Technical tests and adjustment of ventilation and air conditioning systems of air, L, LDNTP, 13 (1990) 